\title{
SUATU UKURAN KESAMAAN HIMPUNAN KABUR INTUITIONISTIC BERNILAI INTERVAL DAN APLIKASINYA UNTUK PENGENALAN POLA
}

\author{
JUNDA SYAHWIDAN, NOVA NOLIZA BAKAR \\ Jurusan Matematika, \\ Fakultas Matematika dan Ilmu Pengetahuan Alam, Universitas Andalas, \\ Kampus UNAND Limau Manis Padang, Indonesia, \\ email jundasyahwildan@rocketmail.com
}

\begin{abstract}
Abstrak. Dalam kehidupan sehari-hari biasanya terjadi berbagai kasus yang rumit, dimana kasus-kasus tersebut banyak sekali mengandung unsur ketidakpastian. Zadeh [6] memperkenalkan suatu teori baru yaitu himpunan kabur (fuzzy set). Kemudian semakin berkembang ilmu pengetahuan, banyak bentuk umum dari fuzzy set yang diusulkan, diantaranya teori himpunan kabur intuitionistic bernilai interval (IvIFS) yang diusulkan oleh Atanassov, merupakan generalisasi dari teori himpunan kabur bernilai interval (IvFS) dan himpunan kabur intuitionistic (IFS). Salah satu topik penting dalam teori himpunan kabur yaitu ukuran kesamaan himpunan kabur intuitionistic (IFS). Pada tulisan ini akan dibahas mengenai metode untuk menghitung ukuran kesamaan antara himpunan kabur intuitionistic bernilai interval (IvIFS) berdasarkan metrik Hausdorff serta aplikasinya
\end{abstract}

Kata Kunci: Himpunan kabur, himpunan kabur intuitionistic, himpunan kabur bernilai interval, himpunan kabur intuitionistic bernilai interval

\section{Pendahuluan}

Prof.L.A.Zadeh [6] pada tahun 1965 pertama kali memperkenalkan teori baru yaitu teori himpunan kabur. Zadeh [6] mendefinisikan suatu himpunan fuzzy atas X sebagai koleksi dari pasangan terurut $(\mathrm{x}, \mu(x)), \forall x \in X$ dimana derajat keanggotaan $\mu(x) \in[0,1]$.

Kemudian semakin berkembang ilmu pengetahuan, banyak bentuk umum dari fuzzy set yang diusulkan, diantaranya Konsep himpunan kabur intuitionistic bernilai interval (IvIFS) yang diusulkan oleh Atanassov, merupakan generalisasi konsep himpunan kabur bernilai interval (IvIFS) dan himpunan kabur intuitionistic (IFS) [1].

Salah satu topik penting dalam teori himpunan kabur yaitu ukuran kesamaan himpunan kabur intuitionistic (IFS). Ukuran kesamaan IFS digunakan untuk memperkirakan tingkat kesamaan antara dua IFS. Szimidt dan Kacprzyk [5] mendefinisikan ukuran kesamaan dengan menggunakan ukuran jarak yang melibatkan kesamaan dan ketidaksamaan.

Seperti yang diketahui, ukuran kesamaan cukup penting dalam beberapa bidang aplikasi. Baru-baru ini, banyak cara untuk menghitung ukuran kesamaan antara himpunan kabur intuitionistic (IFS) dan himpunan kabur bernilai interval (IvFS) 
seperti yang telah diusulkan dalam [7]. Pada penelitian ini akan mengulas kembali apa yang dibahas pada [8] yaitu menghitung ukuran kesamaan antara IvIFS berdasarkan metrik Hausdorff.

\section{Landasan Teori}

\subsection{Himpunan Kabur (Fuzzy Set)}

Definisi 2.1. [4] Misalkan U adalah himpunan semesta. Suatu himpunan kabur (fuzzy set) $X$ atas $U$ dapat didefinisikan sebagai

$$
X=\left\{\left(u, \mu_{x}(u)\right) \mid u \in U, \mu_{x}(u) \in[0,1]\right\}
$$

dimana $\mu_{x}: U \rightarrow[0,1]$ disebut fungsi keanggotaan $X$ atas $U$.

\subsection{Himpunan Kabur Intuitionistik (Intuitionistic Fuzzy Set)}

Himpunan kabur intuitionistic merupakan himpunan kabur yang memperhitungkan nilai keanggotaan dan non keanggotaan dalam proses pengambilan keputusan.

Definisi 2.2. [1] Misalkan $X=\left\{x_{1}, x_{2}, \cdots, x_{n}\right\}$ adalah himpunan. Suatu himpunan kabur intuitionistic A pada $X$ dapat didefinisikan dalam bentuk himpunan pasangan terurut

$$
A=\left\{\left(x, \mu_{A}(x), \nu_{A}(x)\right) \mid x \in X\right\}
$$

dimana $\mu_{A}: X \rightarrow[0,1]$ disebut fungsi keanggotaan $A$ atas $X$ dan $\nu_{A}: X \rightarrow[0,1]$ disebut fungsi ketidakanggotaan $A$ atas $X$, dengan kondisi

$$
0 \leq \mu_{A}(x)+\nu_{A}(x) \leq 1, \forall x \in X .
$$

Definisi 2.3. [1] Misalkan $X=\left\{x_{1}, x_{2}, \cdots, x_{n}\right\}$ suatu himpunan. Himpunan $A$ dan $B$ adalah himpunan kabur intuitionistic, maka didefinisikan operasi dan hubungan sebagai berikut:

(1) $A^{c}=\left\{\left(x, \nu_{A}(x), \mu_{A}(x)\right) \mid x \in X\right\}$,

(2) $A \cap B=\left\{\left(x, \min \left\{\mu_{A}, \mu_{B}\right\}, \max \left\{\nu_{A}, \nu_{B}\right\}\right) \mid x \in X\right\}$,

(3) $A \cup B=\left\{\left(x, \max \left\{\mu_{A}, \mu_{B}\right\}, \min \left\{\nu_{A}, \nu_{B}\right\}\right) \mid x \in X\right\}$.

\subsection{Himpunan Kabur Bernilai Interval (Interval Valued Fuzzy Set)}

Suatu generalisasi dari himpunan kabur yang diajukan oleh beberapa peneliti adalah himpunan kabur bernilai interval (Interval Valued Fuzzy Set).

Definisi 2.4. [2] Misalkan $X$ adalah himpunan semesta dan int $(0,1)$ menunjukkan semua subinterval tertutup dari interval [0, 1]. Sebuah himpunan kabur bernilai interval (IvFS) $A$ atas $X$ didefinisikan sebagai

$$
A=\left\{\left(x, M_{A}(x)\right) \mid x \in X\right\}
$$

dengan $M_{A}: X \rightarrow \operatorname{int}(0,1)$ menunjukkan derajat keanggotaan bernilai interval $A$ atas $X$. 


\subsection{Himpunan Kabur Intuitionistik Bernilai Interval (Interval Valued Intuitionistic Fuzzy Set)}

Terkadang derajat keanggotaan dari himpunan kabur intuitionistic (IFS) tidak dapat diperkirakan secara tepat (real), namun dapat diberikan rentang nilai. Dalam kasus tersebut, Atanassov dan Gargov [2] memperkenalkan tentang himpunan kabur intuitionistic bernilai interval.

Definisi 2.5. [8] Misalkan $X$ adalah himpunan semesta dan int $(0,1)$ menunjukkan semua subinterval tertutup dari interval $[0,1]$. Sebuah himpunan kabur intuitionistic bernilai interval (IvIFS) $A$ atas $X$ didefinisikan sebagai

$$
A=\left\{\left(x, M_{A}(x), N_{A}(x)\right) \mid x \in X\right\}
$$

dengan

$$
M_{A}: X \rightarrow \operatorname{int}(0,1), \operatorname{dan} N_{A}: X \rightarrow \operatorname{int}(0,1),
$$

dimana

$$
M_{A}(x)=\left[\inf M_{A}(x), \sup M_{A}(x)\right], \text { dan } N_{A}(x)=\left[\inf N_{A}(x), \sup N_{A}(x)\right],
$$

masing-masing menunjukkan derajat keanggotaan bernilai interval dan derajat ketidakanggotaan bernilai interval $A$ atas $X$. Dan memenuhi kondisi

$$
0 \leqslant \sup M_{A}(x)+\sup N_{A}(x) \leqslant 1 .
$$

\subsection{Metrik Hausdorff}

Untuk menghitung ukuran jarak dan ukuran kesamaan antara himpunan kabur intuitionistic bernilai interval (IvIFS) akan digunakan metrik Hausdorff.

Definisi 2.6. [8] Misalkan $A=[a 1, a 2] ; B=[b 1, b 2] \in \operatorname{int}(0,1)$, metrik Hausdorff antara $A$ dan $B$ didefinisikan sebagai:

$$
\begin{aligned}
H(A, B) & =|a 1-b 1| \vee|a 2-b 2| \\
& =\max \{|a 1-b 1|,|a 2-b 2|\}
\end{aligned}
$$

\section{Pembahasan}

\subsection{Ukuran Kesamaan Himpunan Kabur Intuitionistik Bernilai Interval}

Berikut akan dijelaskan tentang ukuran jarak antara dua himpunan kabur bernilai interval (IvFS) dan sifat-sifat dari ukuran jarak dan ukuran kesamaan antara dua himpunan kabur intuitionistic bernilai interval (IvIFS).

Misalkan IvIFS $(X)$ merupakan kumpulan semua himpunan kabur intuitionistic bernilai interval di $X$.

Definisi 3.1. [8] Suatu pemetaan $d: \operatorname{IvIFS}(X) \times \operatorname{IvIFS}(X) \rightarrow[0,1]$ dikatakan sebagai ukuran jarak antara himpunan kabur intuitionistic bernilai interval (IvIFS) jika memenuhi sifat-sifat berikut.

Untuk $A, B, C \in \operatorname{IvIFS}(X)$, berlaku 
(1) $0 \leq d(A, B) \leq 1$

(2) $d(A, B)=0$ jika dan hanya jika $A=B$

(3) $d(A, B)=d(B, A)$

(4) Jika $A \subseteq B \subseteq C$, maka $d(A, B) \leq d(A, C)$ dan $d(B, C) \leq d(A, C)$

(5) $d(A, B)=1$, jika salah satu, yaitu $A=\emptyset$ atau $B=\emptyset$ terpenuhi.

Definisi 3.2. [8] Suatu pemetaan $S: \operatorname{IvIFS}(X) \times \operatorname{IvIFS}(X) \rightarrow[0,1]$ dikatakan sebagai ukuran kesamaan antara himpunan kabur intuitionistic bernilai interval(IvIFS) jika memenuhi sifat-sifat berikut.

Untuk $A, B, C \in \operatorname{IvIFS}(X)$, berlaku

(1) $0 \leq S(A, B) \leq 1$

(2) $S(A, B)=1$ jika dan hanya jika $A=B$

(3) $S(A, B)=S(B, A)$

(4) Jika $A \subseteq B \subseteq C$, maka $S(A, C) \leq S(A, B)$ dan $S(A, C) \leq S(B, C)$

(5) $S(A, B)=0$, jika salah satu, yaitu $A=\emptyset$ atau $B=\emptyset$ terpenuhi.

Misalkan $A, B$ adalah dua himpunan kabur intuitionistic bernilai interval (IvIFS) di semesta $X=\left\{x_{1}, x_{2}, \cdots, x_{n}\right\}$. Asumsikan

$$
\begin{aligned}
& M_{A}\left(x_{i}\right)=\left[\inf M_{A}\left(x_{i}\right), \sup M_{A}\left(x_{i}\right)\right], N_{A}\left(x_{i}\right)=\left[\inf N_{A}\left(x_{i}\right), \sup N_{A}\left(x_{i}\right)\right], \\
& M_{B}\left(x_{i}\right)=\left[\inf M_{B}\left(x_{i}\right), \sup M_{B}\left(x_{i}\right)\right], N_{B}\left(x_{i}\right)=\left[\inf N_{B}\left(x_{i}\right), \sup N_{B}\left(x_{i}\right)\right] .
\end{aligned}
$$

Misalkan

$$
\begin{array}{r}
H\left(M_{A}\left(x_{i}\right), M_{B}\left(x_{i}\right)\right): \text { metrik Hausdorff antara } M_{A}\left(x_{i}\right) \text { dan } M_{B}\left(x_{i}\right), \\
H\left(N_{A}\left(x_{i}\right), N_{B}\left(x_{i}\right)\right): \text { metrik Hausdorff antara } N_{A}\left(x_{i}\right) \text { dan } N_{B}\left(x_{i}\right),
\end{array}
$$

dimana

$$
\begin{aligned}
H\left(M_{A}\left(x_{i}\right), M_{B}\left(x_{i}\right)\right) & =\left|\inf M_{A}\left(x_{i}\right)-\inf M_{B}\left(x_{i}\right)\right| \vee\left|\sup M_{A}\left(x_{i}\right)-\sup M_{B}\left(x_{i}\right)\right|, \\
H\left(N_{A}\left(x_{i}\right), N_{B}\left(x_{i}\right)\right) & =\left|\inf N_{A}\left(x_{i}\right)-\inf N_{B}\left(x_{i}\right)\right| \vee\left|\sup N_{A}\left(x_{i}\right)-\sup N_{B}\left(x_{i}\right)\right| .
\end{aligned}
$$

Dengan menggunakan metrik Hausdorff, maka didefinisikan ukuran jarak antara dua buah IvIFS sebagai berikut:

$$
\begin{aligned}
d_{H}^{p}\left(M_{A}, M_{B}\right) & =\sqrt[p]{\frac{1}{n} \sum_{i=1}^{n}\left[H\left(M_{A}\left(x_{i}\right), M_{B}\left(x_{i}\right)\right)\right]^{p}} \\
d_{H}^{p}\left(N_{A}, N_{B}\right) & =\sqrt[p]{\frac{1}{n} \sum_{i=1}^{n}\left[H\left(N_{A}\left(x_{i}\right), N_{B}\left(x_{i}\right)\right)\right]^{p}}
\end{aligned}
$$

Selanjutnya, didefinisikan ukuran kesamaan antara dua buah IvIFS sebagai berikut:

$$
\begin{aligned}
S_{H}^{p}(A, B) & =\frac{1}{2}\left[S_{H}^{p}\left(M_{A}, M_{B}\right)+S_{H}^{p}\left(N_{A}, N_{B}\right)\right] \\
& =1-\frac{1}{2 \sqrt[p]{n}}\left\{\sqrt[p]{\sum_{i=1}^{n}\left[H\left(M_{A}\left(x_{i}\right), M_{B}\left(x_{i}\right)\right)\right]^{p}}+\sqrt[p]{\sum_{i=1}^{n}\left[H\left(N_{A}\left(x_{i}\right), N_{B}\left(x_{i}\right)\right)\right]^{p}}\right\}
\end{aligned}
$$


untuk $p \in[1,+\infty)$, dimana

$$
S_{H}^{p}\left(M_{A}, M_{B}\right)=1-\sqrt[p]{\frac{1}{n} \sum_{i=1}^{n}\left[H\left(M_{A}\left(x_{i}\right), M_{B}\left(x_{i}\right)\right)\right]^{p}}
$$

menunjukkan tingkat kesamaan dari derajat keanggotaan bernilai interval $M_{A}, M_{B}$, dan

$$
S_{H}^{p}\left(N_{A}, N_{B}\right)=1-\sqrt[p]{\frac{1}{n} \sum_{i=1}^{n}\left[H\left(N_{A}\left(x_{i}\right), N_{B}\left(x_{i}\right)\right)\right]^{p}}
$$

menunjukkan tingkat kesamaan dari derajat ketidakanggotaan bernilai interval $N_{A}, N_{B}$

Teorema 3.3. [8] $S_{H}^{p}(A, B)$ adalah ukuran kesamaan antara dua IvIFS $A$ dan $B$ di $X$.

Proposisi 3.4. [8] Berdasarkan ukuran kesamaan $S_{H}^{p}(A, B)$ antara dua himpunan kabur intuitionistic bernilai interval (IVIFS) $A$ dan B, dapat diperoleh bahwa $d_{H}^{p}(A, B)=1-S_{H}^{p}(A, B)$ adalah ukuran jarak antara himpunan kabur intuitionistic bernilai interval (IvIFS) $A$ dan $B$.

Misalkan $f:[0,1] \rightarrow[0,1]$ adalah suatu fungsi monoton turun dan $S(A, B)=$ $\frac{f\left(d_{H}^{p}(A, B)\right)-f(1)}{f(0)-f(1)}$. Maka $S(A, B)$ adalah ukuran kesamaan yang dibangkitkan oleh fungsi $f$ dan ukuran jarak $d_{H}^{p}(A, B)$.

(1) Ketika memilih fungsi $f, f(x)=1-x$, ukuran kesamaan $\mathrm{S}(\mathrm{A}, \mathrm{B})$ didefinisikan sebagai $S_{H}^{p}(A, B)$

$$
S(A, B)=S_{H}^{p}(A, B) .
$$

(2) Ketika memilih fungsi $f, f(x)=e^{-x}$, ukuran kesamaan $\mathrm{S}(\mathrm{A}, \mathrm{B})$ didefinisikan sebagai

$$
S_{e}^{p}(A, B)=\frac{e^{-d_{H}^{p}(A, B)}-e^{-1}}{1-e^{-1}}
$$

(3) Ketika memilih fungsi $f, f(x)=\frac{1}{1+x}, x \neq-1$, ukuran kesamaan $\mathrm{S}(\mathrm{A}, \mathrm{B})$ didefinisikan sebagai

$$
S_{l}^{p}(A, B)=\frac{1-d_{H}^{p}(A, B)}{1+d_{H}^{p}(A, B)}
$$

\section{Aplikasi Ukuran Kesamaan Himpunan Kabur Intuitionistic Bernilai Interval}

Aplikasi dari himpunan kabur intuitionistic bernilai interval sebagai kombinasi dari himpunan kabur bernilai interval dengan himpunan kabur intuitionistic, telah terbukti banyak diterapkan dalam banyak penelitian seperti pengambilan keputusan, pengenalan pola [11], dan diagnosis medis. Berikut diberikan satu contoh numerik 
untuk menunjukkan penerapan ukuran kesamaan yang diajukan IvIFS terhadap pengenalan pola.

Contoh 4.1. Misal diberikan tiga pola himpunan kabur intuitionistic bernilai interval (IvIFS) di $X=\left\{x_{1}, x_{2}, x_{3}\right\}$, yaitu:

$A_{1}=\left\{\left(x_{1},[0,8 ; 0,9],[0 ; 0,1]\right),\left(x_{2},[0,1 ; 0,2],[0,5 ; 0,7]\right),\left(x_{3},[0,4 ; 0,6],[0,1 ; 0,2]\right) \mid x \in X\right\}$,

$A_{2}=\left\{\left(x_{1},[0,5 ; 0,6],[0,2 ; 0,4]\right),\left(x_{2},[0,8 ; 0,9],[0 ; 0,1]\right),\left(x_{3},[0,2 ; 0,4],[0,4 ; 0,5]\right) \mid x \in X\right\}$,

$A_{3}=\left\{\left(x_{1},[0,1 ; 0,2],[0,5 ; 0,6]\right),\left(x_{2},[0,5 ; 0,6],[0,2 ; 0,3]\right),\left(x_{3},[0,7 ; 0,9],[0 ; 0,1]\right) \mid x \in X\right\}$,

dan diberikan pola IvIFS lain

$B=\left\{\left(x_{1},[0,4 ; 0,5],[0,1 ; 0,3]\right),\left(x_{2},[0,7 ; 0,8],[0,1 ; 0,1]\right),\left(x_{3},[0,3 ; 0,4],[0,5 ; 0,6]\right) \mid x \in X\right\}$.

Akan ditentukan pola mana dari pola IvIFS $A_{1}, A_{2}, A_{3}$ yang sama dengan pola IvIFS B.

Berdasarkan Definisi 3.2, akan dihitung ukuran kesamaan antara pola baru B dengan masing-masing pola $A_{i}$ yang diketahui, $i=1,2,3$. Ukuran kesamaan antara himpunan kabur intuitionistic bernilai interval (IvIFS), dapat dilakukan dengan mengambil parameter $p=1,2,3,4,5$.

Tabel 1. Tabel $S_{H}^{p}\left(B, A_{i}\right), i \in\{1,2,3\}$

\begin{tabular}{|r|r|r|r|}
\hline$p$ & \multicolumn{1}{|c|}{$S(B, A 1)$} & \multicolumn{1}{|c|}{$S(B, A 2)$} & \multicolumn{1}{l|}{$S(B, A 3)$} \\
\hline 1 & 0.6 & 0.9 & 0.65 \\
\hline 2 & 0.56795062 & 0.9 & 0.628 \\
\hline 3 & 0.542114303 & 0.9 & 0.610072 \\
\hline 4 & 0.521858763 & 0.9 & 0.595149 \\
\hline 5 & 0.50593105 & 0.9 & 0.583184 \\
\hline
\end{tabular}

Dari tabel di atas, dapat dilihat pengaruh dari nilai p terhadap ukuran kesamaan. Berdasarkan Definisi 3.2 bahwa dua himpunan kabur intuitionistic bernilai interval dikatakan sama apabila nilai ukuran kesamaan antara keduanya mendekati 1, maka dari tabel di atas dapat dilihat bahwa nilai ukuran kesamaan mana yang mendekati 1. Maka dapat disimpulkan bahwa pola IvIFS B memiliki kesamaan dengan pola IvIFS $A_{2}$, karena nilai ukuran kesamaannya mendekati 1 untuk parameter $p=1, p=2, p=3, p=4$, dan $p=5$.

\section{Kesimpulan}

Himpunan kabur intuitionistic bernilai interval (IvIFS) merupakan penggabungan teori himpunan kabur bernilai interval dan himpunan kabur intuitionistic (IFS). 
Metode yang digunakan untuk menghitung ukuran jarak dan ukuran kesamaan antara IvIFS A dan B, yaitu metode metrik Hausdorff.

Dari pembahasan dan aplikasi dapat disimpulkan bahwa :

(1) Misalkan A dan B adalah himpunan kabur intuitionistic bernilai interval, ukuran kesamaan antara dua IvIFS A dan B dengan berdasarkan metrik Hausdorff, yaitu:

$$
\begin{aligned}
S_{H}^{p}(A, B)= & \frac{1}{2}\left[S_{H}^{p}\left(M_{A}, M_{B}\right)+S_{H}^{p}\left(N_{A}, N_{B}\right)\right] \\
= & 1-\frac{1}{2 \sqrt[p]{n}} \\
& \left\{\sqrt[p]{\sum_{i=1}^{n}\left[H\left(M_{A}\left(x_{i}\right), M_{B}\left(x_{i}\right)\right)\right]^{p}}+\sqrt[p]{\sum_{i=1}^{n}\left[H\left(N_{A}\left(x_{i}\right), N_{B}\left(x_{i}\right)\right)\right]^{p}}\right\}
\end{aligned}
$$

untuk $\mathrm{p} \in[1,+\infty)$.

(2) Misalkan $f:[0,1] \rightarrow[0,1]$ suatu fungsi monoton turun dan $S(A, B)=$ $\frac{f\left(d_{H}^{p}(A, B)\right)-f(1)}{f(0)-f(1)}$, maka $S(A, B)$ adalah ukuran kesamaan yang dibangkitkan oleh fungsi $f$ dan ukuran jarak $d_{H}^{p}(A, B)$.

(a) Ketika memilih fungsi $f, f(x)=1-x$, ukuran kesamaan $\mathrm{S}(\mathrm{A}, \mathrm{B})$ didefinisikan sebagai $S_{H}^{p}(A, B)$

$$
S(A, B)=S_{H}^{p}(A, B) .
$$

(b) Ketika memilih fungsi $f, f(x)=e^{-x}$, ukuran kesamaan $\mathrm{S}(\mathrm{A}, \mathrm{B})$ didefinisikan sebagai

$$
S_{e}^{p}(A, B)=\frac{e^{-d_{H}^{p}(A, B)}-e^{-1}}{1-e^{-1}}
$$

(c) Ketika memilih fungsi $f, f(x)=\frac{1}{1+x}, x \neq-1$, ukuran kesamaan S(A,B) didefinisikan sebagai

$$
S_{l}^{p}(A, B)=\frac{1-d_{H}^{p}(A, B)}{1+d_{H}^{p}(A, B)}
$$

(3) Untuk mengetahui dan mengelompokkan suatu pola himpunan kabur intuitionistic bernilai interval yang baru, dapat diselesaikan dengan menghitung nilai ukuran kesamaan antara dua himpunan kabur intuitionistic bernilai interval berdasarkan metrik Hausdorff.

\section{Ucapan Terima kasih}

Penulis mengucapkan terima kasih kepada Bapak Admi Nazra, Ibu Lyra Yulianti, Ibu Monika Rianti Helmi dan Bapak Jenizon yang telah memberikan masukan dan saran sehingga makalah ini dapat diselesaikan dengan baik. 
Ukuran Kesamaan Himpunan Kabur Intuitionistic Bernilai Interval 83

\section{Daftar Pustaka}

[1] Atanassov, K.T. 1986. Intuitionistic Fuzzy Sets. Fuzzy Sets and System 20 (1), pp $87-96$

[2] Atanassov, K.T, G. Gargov. 1989. Interval-valued intuitionistic fuzzy sets. Fuzzy Sets and Systems. 31: $343-349$

[3] Grzegorzewski, P. 2004. Distances between intuitionistic fuzzy sets and/or interval-valued fuzzy sets based on the Hausdorff metric. Fuzzy Sets and Systems, 148(2), $319-328$

[4] Maji, P. K, Biswas, R dan Roy, A. R. 2001.Fuzzy Soft Sets. Journal of Fuzzy Mathematics 9 (3) : $589-602$

[5] Szmidt, E. J. Kacprzyk. 2004. A concept of similarity for intuitionistic fuzzy sets and its application in group decision making. in: Proceedings of International Joint Conference on Neural Networks and IEEE International Conference on Fuzzy Systems, Hungary

[6] Zadeh, L.A. 1965. Fuzzy Sets. Information and Control 8 : 338 - 353

[7] Zeng, W.Y, Q. Yin. 2007. Similarity measure of interval-valued fuzzy sets and application to pattern recognition, The Fifth International Conference on Fuzzy System and Knowledge Discovery

[8] Zhang, Q. Yao, H. and Zhang, Z. 2011. Some similarity measures of intervalvalued intuitionistic fuzzy sets and alication to pattern recognition. Applied Mechanics and Materials, Vols 44-47, pp 3888 - 3892 